\title{
Pengaruh Kompetensi Dan Sistem Pengendalian Internal Terhadap Akuntabilitas Pemerintah Desa Dalam Mengelola Alokasi Dana Desa
}

\author{
Sahala Purba ${ }^{1}$, Rintan Saragih ${ }^{2}$, Tika Meisiska Br Sembiring ${ }^{3}$ \\ 1,2,3Prodi Akuntansi Fakultas Ekonomi Universitas Methodist Indonesia \\ Email: 1sahala.purba@yahoo.com, 2rin_saragih@yahoo.com, 3tikamaysiska@gmail.com
}

\begin{abstract}
This study aims to examine and analyze the effect of competence and internal control system on village government accountability in managing village fund allocations and to test and analyze the effect of competence and internal control system jointly on village government accountability in managing village fund allocations. This type of research is quantitative research and uses primary data. The population in this study were village officials in Tanah Pinem District and the sample used the census method. The data collection method used was a questionnaire given to village officials in Tanah Pinem District, amounting to 48 people. The data analysis method used in this research is descriptive analysis and multiple linear regression. The results of this study indicate that competence has a positive but not significant effect on village government accountability, while partially the internal control system has a positive and significant effect on village government accountability. Simultaneously, competence and internal control system have a positive and significant effect on village government accountability.
\end{abstract}

Keywords: Competence, Internal Control System and Village Government Accountability

\begin{abstract}
Abstrak
Penelitian ini bertujuan untuk menguji dan menganalisis pengaruh kompetensi dan sistem pengendalian internal terhadap akuntabilitas pemerintah desa dalam mengelola alokasi dana desa dan untuk menguji dan menganalisis pengaruh kompetensi dan sistem pengendalian internal secara bersama-sama terhadap akuntabilitas pemerintah desa dalam mengelola alokasi dana desa. Jenis penelitian ini merupakan penelitian kuantitatif dan menggunakan data primer. Populasi dalam penelitian ini adalah perangkat desa pada Kecamatan Tanah Pinem dan sampel menggunakan metode sensus. Metode pengumpulan data yang digunakan adalah kuesioner yang diberikan kepada perangkat desa yang ada di Kecamatan Tanah Pinem yang berjumlah 48 orang. Metode analisis data yang digunakan dalam penelitian ini adalah analisis deskriptif dan regresi linier berganda. Hasil penelitian ini menunjukkan bahwa kompetensi berpengaruh positif tetapi tidak signifikan terhadap akuntabilitas pemerintah desa sedangakan secara parsial sistem pengendalian internal berpengaruh positif dan signifikan terhadap akuntabilitas pemerintah desa. Secara simultan kompetensi dan sistem pengendalian internal berpengaruh positif dan signifikan terhadap akuntabilitas pemerintah desa.
\end{abstract}

Kata Kunci : Kompetensi, Sistem Pengendalian Internal dan Akuntabilitas Pemerintah Desa

\section{PENDAHULUAN}

Akuntabilitas pemerintah desa banyak yang menjadi masalah salah satunya sesuai dengan pernyataan Ombudsman yang menerima banyak laporan dari masyarkaat desa yang menyangkut dalam pengelolaan dana desa. Antara lain: dugaan tidak transparans, markup, fiktif, proyek tidak sesuai kebutuhan, tidak sesuai aturan dalam pengelolaan dana desa oleh oknum kepala desa. Dalam sambutannya menyampaikan bahwa saat ini menerima 36 laporan masyarakat yang masuk ke Ombudsman terkait masalah desa. Berdasarkan laporan yang diterima oleh Ombudsman dugaan yang terkait dalam masalah desa tersebut adalah: Dugaan maladministrasinya berbagai macam, mulai dari tidak melayani, tidak patut, tidak prosedural dan tidak sesuai aturan.

Akuntabilitas pemerintah desa, peneliti hanya membatasi 2 variabel independen yaitu kompetensi dan sistem pengendalian internal. Menurut peneliti bahwa kedua variabel tersebut 
berpengaruh terhadap akuntabilitas pemerintah desa dalam mengelola alokasi dana desa pada desa yang terdapat di Kecamatan Tanah Pinem.

Tabel 1.1

Ringkasan Riset GAP

\begin{tabular}{|c|c|c|c|}
\hline $\begin{array}{l}\text { Variabel } \\
\text { Independen }\end{array}$ & $\begin{array}{l}\text { Variabel } \\
\text { Dependen }\end{array}$ & Berpengaruh & Tidak Berpengaruh \\
\hline Kompetensi & $\begin{array}{l}\text { Akuntabilitas } \\
\text { Pemerintah Desa }\end{array}$ & $\begin{array}{lr}\text { Mada, Kalangi,dan } \\
\text { Gamaliel(2017); } \\
\text { Mualifu,Guspul dan } \\
\text { Hermawan } & \text { (2019); } \\
\text { Devi,Antong } & \text { dan } \\
\text { Bachri (2020) } & \end{array}$ & $\begin{array}{l}\text { Sweetenia } \\
\text { et.al(2019); } \\
\text { Syafaruddin,Kamase } \\
\text { dan Mursalim (2019) }\end{array}$ \\
\hline $\begin{array}{l}\text { Sistem } \\
\text { pengendalian } \\
\text { internal }\end{array}$ & & $\begin{array}{l}\text { Widyatama,Novita,dan } \\
\text { Diarespati(2017); } \\
\text { Khimayah,Noor } \\
\text { (2018); } \\
\text { Mualifu,Guspul } \\
\text { dan,Hermawan (2019) }\end{array}$ & $\begin{array}{l}\text { Pahlawan, } \\
\text { Wijayanti, } \\
\text { Suhendro(2020) }\end{array}$ \\
\hline
\end{tabular}

Sumber : Dari Berbagai Jurnal, 2020

Berdasarkan latar belakang diatas maka peneliti tertarik mengangkat judul tentang "Pengaruh Kompetensi dan Sistem Pengendalian Internal Terhadap Akuntabilitas Pemerintah Desa dalam Mengelolah Alokasi Dana Desa "(Studi kasus Desa Kecamatan Tanah Pinem )

\section{Kajian Pustaka, Kerangka Pemikiran, dan Hipotesis}

Akuntabilitas merupakan suatu bentuk kewajiban pertanggungjawaban seorang pememimpin atau suatu organisasi yang memiliki hak dan kewenangan untuk diminta keterangan terkait kinerja untuk mempertanggungjawabkan program pemerintah desa, pengeluran dan pendapatan desa serta memiliki cara yang efisien dalam mengambil keputusan.

Menurut Arifiyadi (2018) Akuntabilitas adalah "kewajiban dari individu atau penguasa yang dipercayakan untuk mengelal sumber daya publik dan yang bersangkutan dengannya kemudian dapat menjawab hal yang menyangkut pertanggungjawabannya". Akuntabilitas terkait erat dengan istrumen untuk kegiatan kontrol terutama dalam hal pencapaian hasil pada pelayanan publik dan menyampaikannya secara transparan kepada masyarakat.

Alokasi Dana Desa (ADD) merupakan kewajiban Pemerintah Kabupaten/Kota untuk mengalokasikan kedalam APBD melalui dana perimbangan setelah dikurangi Dana Alokasi Khusus (DAK) untuk kemudian disalurkan ke Rekening Kas Desa (RKD), dimaksud pada ayat 1 dialokasikan paling sedikit 10\% (sepuluh per seratus) dari dana perimbangan yang diterima Kabupaten/Kota dalam Anggaran Pendapatan dan Belanja Daerah setelah dikurangi Dana Alokasi Khusus, (Alokasi Dana Desa (ADD) diatur dalam pasal 96 ayat 1 dan 2 PP 47 tahun 2015 perubahan atas PP 43 tahun 2014 sebagai peraturan pelaksana UU Desa).

Alokasi dana desa merupakan salah satu anggaran keuangan yang diberikan oleh pemerintah kepada desa, ADD berasal dari APBD Kabupaten/Kota yang sumbernya dari dana perimbangan keuangan pusat serta daerah yang diterima oleh kabupaten(Widiyatama dkk,2017).

Menurut Susanto (2002) Kompetensi adalah segala bentuk perwujudan, ekspresi, dan representasi dari motif, pengetahuan, sikap, perilaku utama agar mampu melaksanakan pekerjaan dengan sangat baik atau yang membedakan antara kinerja rata-rata dengan kinerja superior.

Menurut Stephen Robbin (2007:38) Kompetensi menurut Stephen Robbin adalah kemampuan (ability) atau kapasitas seseorang untuk mengerjakan berbagai tugas dalam suatu pekerjaan, dimana kemampuan ini ditentukan oleh dua faktor yang kemampuan intelektual dan kemampuan fisik.

Dalam Peraturan Pemerintah Nomor 60 Tahun 2008 Pasal 1 tentang sistem pengendalian intern adalah proses yang integral pada tindakan dan kegiatan yang dilakukan secara terus menerus oleh pimpinan dan seluruh pegawai untuk memebrikan keyakinan 
memadai atas tercapainya tujuan organisasi melalui kegiatan yang efektif dan efisien, keandalan pelaporan keuangan, pengamanan asset Negara terhadap peraturan perudangundangan.

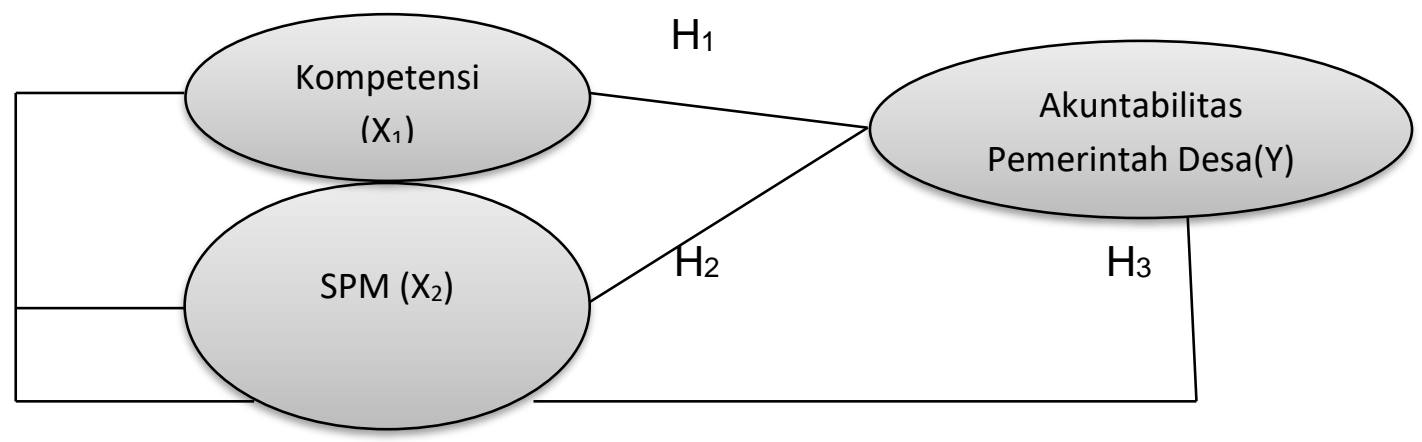

Permasalahan, kajian pustaka dan kerangka pemikiran ini, maka variabel akan berpengaruh atau tidak terhadap Akutailitas pemerintah desa dapat diuji melalui dugaan hipotesis sebagai berikut:

$\mathrm{H}_{1}$ : Kompetensi berpengaruh positif dan signifikan terhadap Akuntabilitas Pemerintah Desa

$\mathrm{H}_{2}$ : Sistem Pengendalian Internal berpengaruh positif dan signifikan terhadap Akuntabilitas Pemerintah Desa

$\mathrm{H}_{3}$ : Kompetensi dan Sistem Pengendalian Internal Berpengaruh Secara Bersama-Sama Terhadap Akuntabilitas Pemerintah Desa

\section{Objek dan Metode Penelitian}

Penelitian ini dilakukan pada Desa Kecamatan Tanah Pinem, waktu penelitan yang dilakukan oleh peneliti dimulai dari penentuam judul sampai akhir penelitian dilakukan. Populasi dalam penelitian ini adalah perangkat desa di desa Kecamatan Tanah Pinem, Perangkat desa terdiri dari Kepala Desa, Sekretaris Desa, Bendahara dan BPD. Peneliti mengambil atau memilih populasi 19 Desa di Kecamatan Tanah Pinem. Kriteria yang digunakan untuk memilih kriteria responden adalah aparatur dan tim penjabat pemerintah desa yang melaksanakan fungsi dalam pengelolaan desa yang terdiri dari :

1. Kepala desa sebagai penanggung jawab

2. Sekretaris desa sebagai koordinator pengelola keuangan desa

3. Bendahara desa sebagai administrasi keuangan

4. Badan permusyarawatan desa (BPD) sebagai perwakilan masyarakat

5. Desa yang bisa dijangkau dalam dalam waktu 3 jam dengan menggunakan kendaraan sepeda motor dari kantor camat.

Alasan saya memilih keempat responden tersebut adalah karena perangkat diatas dan masyarakat yang aktif dan lebih mengetahui mengenai pengelolaan dana desa di Kecamatan Tanah Pinem.

Tabel 3.1

Operasional Variabel

\begin{tabular}{|l|lr|l|l|}
\hline Variabel & Definisi & & Indikator & Skala \\
\hline Akuntabilitas & Akuntabilitas & dalam & Menurut Permendagri Nomor 20 Tahun & Interva \\
Pemerintah & pemerintah & desa & 2018 indikator Akuntabilitas Pengelolaan & \\
Desa (Y) & sebagaimana & yang & Keuangan Desa adalah sebagai berikut : & I \\
& diungkapkan & oleh & 1. Perencanaan & \\
& Sukasmanto & dan & 2. Pelaksanaan & \\
& Sumpeno & $(2011)$ & 3. Penatausahaan & \\
& melibatkan kemampuan & 4. Pelaporan & \\
& pemerintah desa untuk & 5. Pertanggungjawaban & \\
& mempertanggungjawabka & & & \\
\hline
\end{tabular}

Lisensi: Creative Commons Attribution 4.0 International (CC BY 4.0) 


\begin{tabular}{|c|c|c|c|}
\hline & $\begin{array}{lr}\mathrm{n} \quad \text { kegiatan } & \text { yang } \\
\text { dilaksanakan dalam } & \text { dengan } \\
\text { kaitannya dananan } & \text { demasalah pembangunan } \\
\text { masal pemerintah desa. }\end{array}$ & & \\
\hline $\begin{array}{l}\text { Kompetensi } \\
\left(X_{1}\right)\end{array}$ & $\begin{array}{lr}\text { Menurut } & \text { Rudana, } 2005 \\
\text { (dalam Widyatama et } \\
\text { al.,2017:6), Kompetensi } \\
\text { mengacu repada } \\
\text { pengetahuan, keahlian } \\
\text { dan kemampuan yang } \\
\text { dimiliki dengan standar } \\
\text { tertentu. }\end{array}$ & $\begin{array}{ll}\text { Menurut Rudana (2005:6): } \\
\text { 1. } & \text { pengetahuan (knowledge) } \\
\text { 2. } & \text { keahlian (skills) } \\
\text { 3. } & \text { kemapuan (abilities) }\end{array}$ & $\begin{array}{l}\text { Interva } \\
\text { I }\end{array}$ \\
\hline $\begin{array}{l}\text { Sistem } \\
\text { Pengendalia } \\
\mathrm{n} \text { Internal }\left(\mathrm{X}_{2}\right)\end{array}$ & $\begin{array}{lr}\text { Menurut } & \text { Peraturan } \\
\text { Pemerintah Nomor } 60 \\
\text { Tahun 2008 Sistem } \\
\text { Pengendalian Internal } \\
\text { (SPI) adalah proses yang } \\
\text { integral pada tindakan dan } \\
\text { kegiatan yang dilakukan } \\
\text { secara terus menerus oleh } \\
\text { pimpinan dan seluruh } \\
\text { pegawai rantuk } \\
\text { memberikan keyakinan } \\
\text { memadai atas tercapainya } \\
\text { tujuan organisasi melalui } \\
\text { kegiatan yang efektif dan } \\
\text { efisien. }\end{array}$ & $\begin{array}{l}\text { Menurut Peraturan Pemerintah Nomor } \\
60 \quad \text { Tahun } 2008 \text { indikator Sistem } \\
\text { Pengendalian internal sebagai beriku : } \\
\text { 1. Lingkungan pengendalian } \\
\text { 2. Penilaian Resiko } \\
\text { 3. Kegiatan Pengendalian } \\
\text { 4. Informasi dan Komunikasi } \\
\text { 5. Aktivitas Pengendalian }\end{array}$ & $\begin{array}{l}\text { Interva } \\
\text { I }\end{array}$ \\
\hline
\end{tabular}

Sumber : Dari Berbagai Jurnal, 2021

\section{Hasil Penelitian dan Pembahasan}

Statistik Deskriptif

Pada bagian analisis statistik deskriptif, disajikan distribusi frekuensi dan persentase dari variabel kompetensi, sistem pengendalian internal danakuntabilitas pemerintah desa.

\section{Kompetensi (X1)}

\begin{tabular}{|c|c|c|c|c|c|c|c|c|c|c|c|c|}
\hline \multirow[t]{2}{*}{$\mathbf{P}$} & \multicolumn{2}{|c|}{$\begin{array}{l}\text { Sangat } \\
\text { Tidak } \\
\text { Setuju }\end{array}$} & \multicolumn{2}{|c|}{$\begin{array}{l}\text { Tidak } \\
\text { Setuju }\end{array}$} & \multicolumn{2}{|c|}{ Netral } & \multicolumn{2}{|c|}{ Setuju } & \multicolumn{2}{|c|}{$\begin{array}{l}\text { Sangat } \\
\text { Setuju }\end{array}$} & \multicolumn{2}{|c|}{ Total } \\
\hline & $\mathbf{F}$ & $\%$ & $\mathbf{F}$ & $\%$ & $\mathbf{F}$ & $\%$ & $F$ & $\%$ & $F$ & $\%$ & $\mathbf{F}$ & $\%$ \\
\hline PY 1 & 0 & 0 & 0 & 0 & 2 & 4,2 & 18 & 37,5 & 28 & 58,3 & & $100 \%$ \\
\hline PY2 & 0 & 0 & 0 & 0 & 2 & 4,2 & 25 & 52,1 & 21 & 43,8 & & $100 \%$ \\
\hline PY 3 & 0 & 0 & 0 & 0 & 2 & 4,2 & 25 & 52,1 & 21 & 43,8 & & $100 \%$ \\
\hline PY 4 & 0 & 0 & 0 & 0 & 5 & 10,4 & 20 & 41,7 & 23 & 47,9 & & $100 \%$ \\
\hline
\end{tabular}




\begin{tabular}{|c|c|c|c|c|c|c|c|c|c|c|c|}
\hline PY 5 & 0 & 0 & 0 & 0 & 2 & 4,2 & 18 & 37,5 & 28 & 58,3 & $100 \%$ \\
\hline PY 6 & 0 & 0 & 0 & 0 & 1 & 2,1 & 26 & 54,2 & 21 & 43,8 & $100 \%$ \\
\hline PY 7 & 0 & 0 & 0 & 0 & 1 & 2,1 & 27 & 56,3 & 20 & 41,7 & $100 \%$ \\
\hline PY 8 & 0 & 0 & 0 & 0 & 2 & 4,2 & 18 & 37,5 & 28 & 58,3 & $100 \%$ \\
\hline PY 9 & 0 & 0 & 0 & 0 & 2 & 4,2 & 18 & 37,5 & 28 & 58,3 & $100 \%$ \\
\hline PY 10 & 0 & 0 & 0 & 0 & 1 & 2,1 & 25 & 52,1 & 22 & 45,8 & $100 \%$ \\
\hline PY 11 & 0 & 0 & 0 & 0 & 5 & 10,4 & 20 & 41,7 & 23 & 47,9 & $100 \%$ \\
\hline
\end{tabular}

1. Untuk pernyataan ke-7 (PY7), terdapat $0(0 \%)$ responden menjawab STS, responden menjawab TS sebanyak $0(0 \%)$, terdapat $1(2,1 \%)$ responden menjawab $\mathrm{N}$, responden yang menjawab $\mathrm{S}$ sebanyak $27(56,3 \%)$, responden yang menjawab SS sebanyak $20(41,7 \%)$.

2. Untuk pernyataan ke-8 (PY8), terdapat $0(0 \%)$ responden menjawab STS, responden menjawab TS sebanyak $0(0 \%)$,terdapat $2(4,2 \%)$ responden menjawab $\mathrm{N}$, responden yang menjawab $\mathrm{S}$ sebanyak $18(37,5 \%)$, responden yang menjawab SS sebanyak $18(58,3 \%)$.

3. Untuk pernyataan ke-9 (PY9), terdapat $0(0 \%)$ responden menjawab STS, responden menjawab TS sebanyak $0(0 \%)$,terdapat $2(4,2 \%)$ responden menjawab $\mathrm{N}$, responden yang menjawab $\mathrm{S}$ sebanyak $18(37,5 \%)$, responden yang menjawab SS sebanyak $18(58,3 \%)$.

4. Untuk pernyataan ke-10 (PY10), terdapat $0(0 \%)$ responden menjawab STS, responden menjawab TS sebanyak $0(0 \%)$,terdapat $1(2,1 \%)$ responden menjawab $\mathrm{N}$, responden yang menjawab $\mathrm{S}$ sebanyak $25(52,1 \%)$, responden yang menjawab SS sebayak $22(45,8 \%)$.

5. Untuk pernyataan ke-11 (PY11), terdapat $0(0 \%)$ responden menjawab STS, responden menjawab TS sebanyak $0(0 \%)$, terdapat $5(10,4 \%)$ responden menjawab N, responden yang menjawab S sebanyak $20(41,7 \%)$, responden yang menjawab SS sebanyak $23(47,9 \%)$.

Tabel 4.13 Hasil Uji Multikolonearitas

\begin{tabular}{|c|c|c|c|c|c|c|}
\hline \multicolumn{7}{|c|}{ Coefficients $^{a}$} \\
\hline \multirow{2}{*}{\multicolumn{2}{|c|}{ Model }} & \multicolumn{2}{|c|}{$\begin{array}{l}\text { Unstandardized } \\
\text { Coefficients }\end{array}$} & \multirow{2}{*}{$\begin{array}{l}\text { Standardized } \\
\text { Coefficients } \\
\text { Beta } \\
\end{array}$} & \multicolumn{2}{|l|}{$\begin{array}{l}\text { Collinearity } \\
\text { Statistics }\end{array}$} \\
\hline & & $\mathrm{B}$ & Std. Error & & Tolerance & VIF \\
\hline \multirow[t]{3}{*}{1} & (Constant) & 22.893 & 3.717 & & & \\
\hline & $\mathrm{X} 1$ & .040 & .053 & .106 & .962 & 1.040 \\
\hline & $\mathrm{X} 2$ & .207 & .087 & .334 & .962 & 1.040 \\
\hline
\end{tabular}

a. Dependent Variable: $Y$ 


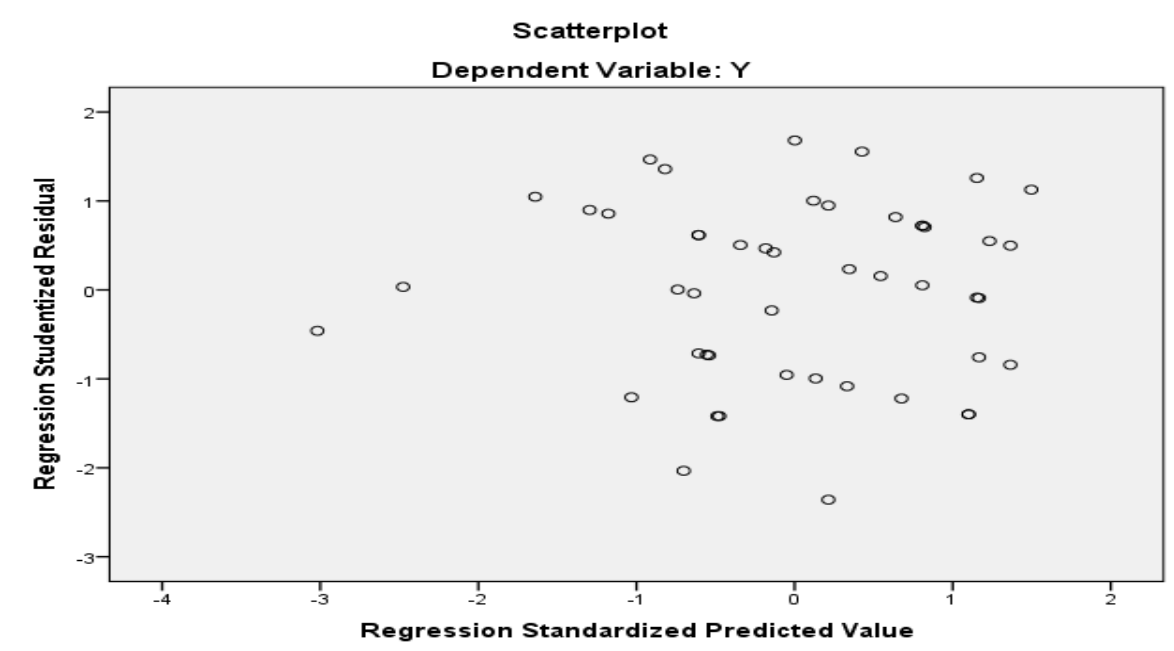

Tabel 4.17

Uji Signifikansi Pengaruh Parsial (Uji Statistik t)

Coefficients $^{\mathrm{a}}$

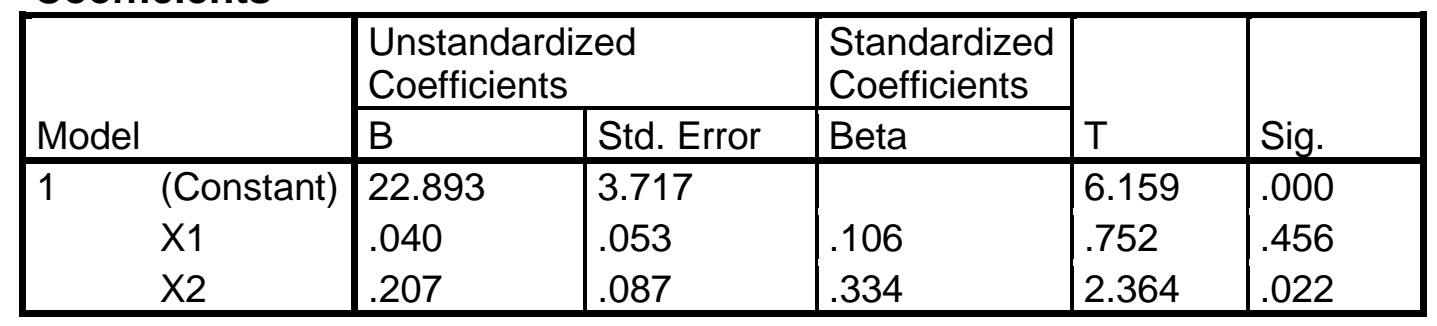

a. Dependent Variable: $Y$

Sumber : Data yang diolah SPSS,2021

Pengaruh Kompetensi Secara Parsial Terhadap Akuntabilitas Pemerintah Desa

Hipotesis pertama yang diajukan menyatakan bahwa kompetensi secara parsial mempunyai pengaruh positif dan signifikan terhadap akuntabilitas pemerintah desa dalam mengelola alokasi dana desa. Berdasarkan hasil SPSS terdapat nilai t hitung 0,752<t tabel 2,014 dan nilai signifikansinya sebesar $0,456>0,05$. Berdasarkan hasil SPSS menyatakan bahwa kompetensi tidak berpengaruh dan tidak signifikan sehingga hipotesanya ditolak. Kompetensi yang dilaksanakan dengan baik, maka akuntabilitas pemerintah desa akan meningkat, kurangnya penerapan kompetensi akan mempengaruhi kinerja atau perkembangan akuntabilitas pemerintah desa. Adanya kompetensi ditunjukkan agar dapat lebih memahami tugas dan tanggungjawab, kemampuan serta sikap dalam melayani masyarat agar lebih ditingkatkan.

Pengaruh Sistem Pengendalian Internal Secara Parsial Terhadap Akuntabilitas Pemerintah

Desa

Hipotesa kedua yang diajukan menyatakan bahwa sistem pengendalian internal secara parsial berpengaruh positif dan signifikan terhadap akuntabilitas pemerintah desa. Variabel sistem pengendalian internal memiliki thitung 2,364 > tabel 2,014 dan dinyatakan signifikan karena angka Sig $<\alpha(0,05)$ yaitu nilai signifikansinya sebesar 0,022 . Dengan demikian hipotesa kedua yang menyatakan bahwa sistem pengendalian internal berpengaruh positif dan signifikan terhadap akuntabilitas pemerintah desa hipotensanya dapat diterima.

Sesuai dengan PP No.60 Tahun 2008, Sistem Pengendalian Internal (SPI) ditunjukkan untuk mencapai tujuan organisasi, diantaranya pelaksanaan kegiatan secara efektif dan efisien dihasilkan pelaporan keuangan yang handal, terjaganya aset negara daerah/negara, dan patuh terhadap peraturan perundang-undangan. SPI wajib dilaksanakan di setiap tingkatan pemerintahan baik di tingkat kementrian hingga pemerintahan daerah. Menurut pasal 3 ayat 1 PP No.60 Tahun 2008 adapun indikator yang mengatur sistem pengendalian internal yaitu meliputi: lingkungan pengendalian, penilaian resiko, kegiatan pengendalian, informasi dan komunikasi serta pemantauaan pengendalian internal.

Pengaruh Kompetensi Dan Sistem Pengendalian Internal Secara Simultan Terhadap Akuntabilitas Pemerintah Desa 
Dari hasil analisis regresi dapat diketahui pula bahwa secara bersama-sama variabel independen memiliki pengaruh positif dan signifikan terhadap variabel dependen. Hal ini dibuktikan dari nilai $F$ hitung sebesar $3.559>F$ tabel 2,014 dengan nilai signiifikan sebesar 0,037. Karena Probabilitas lebih kecil dari 0,05 atau 5\% maka model regresi dapat digunakan untuk mengetahui bahwa Kompetensi dan sistem pengendalian internal secara simultan berpengaruh signifikan terhadap akuntabilitas pemerintah desa.

Hal ini berarti Apabila Kompetensi dan sistem pengendalian internal diimplementasikan dengan baik maka dapat meningkatkan akuntabilitas pemerintah desa. Sebalikanya apabila kompetensi dan sistem pengendalian internal tidak diterapkan dengan baik maka akan mengurangi akuntabilitas pemerintah desa .

Hasil penelitian ini menunjukkan pengaruh Kompetensi dan sistem pengendalian internal berpengaruh signifikan dan positif terhadap akuntabilitas pemerintah desa dalam mengelola alokasi dana desa (ADD). Berdasarkan penelitian Devi,Antong dan Bachri (2020), mengatakan bahwa kompetensi dan sistem pengendalian internal berpengaruh terhadap akuntabilitas pemerintah desa.

\section{Kesimpulan dan Saran}

Dari hasil analisis data dan pembahasan yang telah dilakukan dalam penelitian pengaruh kompetensi dan sistem pengendalian internal terhadap akuntabilitas pemerintah desa dalam mengelola alokasi dana desa (studi kasus pada Desa Kecamatan Tanah Pinem), maka dapat ditarik kesimpulan sebagai berikut:

1. Penerapan kompetensi tidak berpengaruh dan tidak signifikan terhadap akuntabilitas pemerintah desa. Hal ini mengindikasikan bahwa apabila penerapan kompetensi tidak dilakukan dengan baik maka akan mengakibatkan akuntabilitas pemerintah desa juga tidak akan dapat berjalan dengan baik.

2. Penerapan sistem pengendalian internal berpengaruh positif dan signifikan terhadap akuntabilitas pemerintah desa. Hal ini mengindekasikan bahwa apabila penerapan sistem pengendalian internal berjalan dengan baik maka akuntabilitas pemerintah desa juga akan semakin baik.

3. Penerapan kompetensi dan sistem pengendalian internal secara bersama-sama berpengaruh terhadap akuntabilitas pemerintah desa maka akan meningkatkan akuntabilitas pemerintah desa. Ini menunjukkan bahwa kompetensi dan sistem pengendalian internal sangat mempengaruhi perkembangan pemerintah desa

Penelitian ini memiliki keterbatasan yang memerlukan perbaikan dan pengembangan dalam penelitian selanjutnya. Keterbatasan dalam penelitian ini antara lain:

1. Objek penelitian ini adalah tidak semua desa pada kecamatan tanah pinem, peneliti hanya mengambil 12 desa saja untuk diteliti sedangkan 7 desa lainnya sulit untuk dijangkau atau diakses melebihi batas waktu tempuh 3 jam.

2. Penelitian ini memilih beberapa koresponden saja antara lain : Kepala Desa, Sekertaris Desa, Bendahara Desa, dan Badan permusyawaratan Desa (BPD).

3. Penelitian ini hanya menggunakan 2 variabel dalam mengukur Akuntabilitas Pemerintah Desa antara lain : Kompetensi dan Sistem Pengendalian Internal.

Berdasarkan hasil penelitian dan pembahasan, terlihat bahwa penerapan kompetensi dan sistempengendalian internal memiliki pengaruh yang cukup besar terhadap akuntabilitas pemerintah desa. Berikut saran yang diusulkan :

1. Bagi Pihak Pemerintah Desa, Yaitu:

a. Bagi pihak kecamatan beserta jajarannya, hendakanya lebih meningkatkan tata kelola pemerintahan yang baik dengan menerapakan prinsip kompetensi dan sistem pengendalian internal untuk mendorong akuntabilitas pemerintah desa yang akuntabel,transparan dan dapat dipertanggungjawabkan.

b. Bagi kepala desa beserta para perangkatnya yang memiliki latar belakang ata pendidkan yang berbed- beda (tidak hanya dari akuntansi) dan apabla pegawai ditempatkan pada posisi penyususan pelaporan pertanggungjawaban supaya dapat diberi pembekalan dasar akuntansi dan mengadakan pelatihan-pelatihan tentang akuntansi sehingga lebih menunjang pada pelaporang keuangan yang berkualitas. 
2. Bagi Peneliti Selanjutnya

a. Menambah refrensi yang lebih banyak lagi dan lebih memperluas objek penelitian seperti meneliti kecamatan lainnya ataupun meneliti kabupaten.

b. Memperbanyak responden dalam penelitian selanjutnya untuk mendapatkan informasi yang lebih jelas dan akurat.

c. Menambah variabel untuk mendukung akuntabilitas pemerintah desa yang lebih baik yang dapat peneliti selanjutnya teliti seperti transparansi(agar dapat dilihat keterbukaan data yang ingin dilihat dan dapat dipertanggungjawabkan), teknologi informasi(memilih teknologi sebagai penambahan variabel dapat mendukung memproses data dengan baik dan maksimal), dan partisipasi masyarakat(ikut serta membangun dan membuka pemikiran serta pengembangan masyarakat) sehingga dapat memperoleh Akuntabilitas Pemerintah Desa yang baik.

\section{Daftar Pustaka}

[1] Armstrong, Michael, 2004. Performance Management. Tugu. Jogjakarta.

[2] Alamsyah. 1997. Mekanisme Pengawasan APBD di Kabupaten Sleman, Tesis S2 MAP, Universitas Gajah Mada, Yogyakarta.

[3] Albugis F. Febriana. (2016). "Penerapan Sistem Akuntansi Keuangan Daerah Dalam Sulawesi Utara".

[4] Arifiyadi, Teguh SH. 2008. Konsep tentang Akuntabilitas dan Implementasinya dilndonesia, Jakarta.

[5] Byars dan Rue,(1997).Human Resource Management.5th Edition. Chicag: McGrw-Hill Companies, Inc.

[6] Committee of Sponsoring Organization (COSO) of The Treadway Commission. 2013. Internal Control -Integrated Framework: Executive Summary. COSO. Mei 2013.

[7] Hopwood, A. Dan Tomkins, C., 1984. Issues In Public SectorAccounting.Oxford: Philip Allan

[8] Lembaga Administrasi Negara. 1999.Pedoman Penyusunan AkuntabilitasKinerja Instansi Pemerintah.Jakarta

[9] Robbins Stephen P, 2007, Perilaku Organisasi, Jilid 1 \& 2,Alih Bahasa :HadyanaPujaatmaka, Indeks Kelompok Gramedia, Jakarta.

[10] Spencer, Lyle M. dan Signe M. Spencer. (2007). Competence at work: Models forSuperior Performance. Canada: John Wiley \& Sons.

[11] UNDP. 1995. "Human Development Report"United Nations Development Programme. NewYork

[12] Wibowo. ( 2007). Manajemen Kinerja. Edisi ketiga.Jakarta: PT.Raja Grafindo Prasada.

[13] Wibowo. (2010). Manajemen Kinerja.Jakarta: Rajawali Press.

[14] Widyatama, A., Novita, L., \& Diarespati, D. (2017). Pengaruh Kompetensi dan Sistem Pengendalian Internal Terhadap Akuntabilitas Pemerintah Desa 